\title{
Ensino de Física: a realidade cotidiana e o conhecimento científico no contexto da escola
}

\author{
Physics Teaching: the daily reality and \\ Scientific Knowledge in the school context \\ Antonio Jorge Sena dos Anjos* \\ Departamento de Física - UEFS \\ Campus Universitário $\mathrm{Km}$ 03, BR 116 \\ Feira de Santana - BA - 44031-460
}

\begin{abstract}
Considerando a problemática existente em torno do ensino de Ciências no contexto da escola básica e sua implicação na formação geral dos estudantes, procuramos fazer algumas reflexões e considerações críticas sobre componentes que interferem diretamente no fazer pedagógico em Ciências, bem como apresentamos algumas sugestões no sentido de melhor adequar o ensino de Ciências em geral e o de Física, em particular, às necessidades e desafios do mundo atual.
\end{abstract}

Palavras-chaves: Ensino de Ciências, Formação de Professores, Currículo das Disciplinas Científicas, Construção de Conhecimento.

Considering the problems related to the teaching of Science in the context of basic schooling and its implication in the general formation of the students, this study aims to reflect on and make critical considerations about the components that directly interfere in the pedagogical practice of Science, and also present some suggestions with the objective of a better adequation of the teaching of general Science and specifically, the teaching of Physics, to the challenges and needs of the present world.

Key-words: Science Teaching, Teachers Formation, Scientific Subjects Program, Knowledge Building.

\section{INTRODUÇÃO}

"Somente aprendemos quando conseguimos atribuir significados aos fatos que nos chegam e a atribuição de significados é sempre uma maneira gostosa de se aprender, quando contextualizados à vida e ao entorno do aprendiz."

- Celso Antunes

Muito se tem falado da necessidade de uma educação de qualidade em Ciências para crianças e jovens em fase de escolarização. As pesquisas em ensino de Ciências [1-4] têm constatado e revelado que a escola não tem cumprido o seu papel de educar cientificamente os alunos.

O ensino das Ciências Naturais nas escolas, via de regra, não tem contribuído para uma educação científica profícua e significativa para os estudantes. A ausência de objetivos coerentes e a indefinição de conteúdos têm contribuído fortemente para o quadro que ora se apresenta a educação em Ciências em nosso país.

Numa tentativa de buscar melhorias, é necessário, conforme Carvalho [4], que o ensino desenvolvido na escola consiga conjugar de forma harmoniosa a dimensão conceitual da aprendizagem com a dimensão formativa e cultural. Nesse sentido:

*Endereço Eletrônico: anjos.antonio@gmail.com
Propõe-se ensinar Ciências a partir do ensino sobre Ciências. O conteúdo curricular ganha novas dimensões ao antigo entendimento do conceito de conteúdo. Passa a incluir, além da dimensão conceitual, as dimensões procedimentais e atitudinais, esta representada pela discussão dos valores do próprio conteúdo [4] (pg. 03).

Dessa forma, ensinar Ciências não implica apenas em submeter os estudantes a uma acumulação de conteúdos científicos, mas sim fazê-los participar de um processo de construção de conceitos que objetive a aculturação científica, proporcionando-lhes oportunidade de pensar, investigar, argumentar, . .., aprender, em vez de fornecer-lhes respostas prontas e acabadas de uma Ciência fechada em si mesma.

Para refletir sobre tal temática, resgatamos momentos de nossa infância-adolescência. Momentos de uma realidade por nós vivenciada entre os estudos na escola (no antigo ginásio, hoje ensino fundamental) e as labutas e aprendizados na oficina de nosso pai, mecânico de carros automotivos, amante da profissão e autodidata nos assuntos concernentes a sua profissão. As experiências na oficina nos trazem boas e inesquecíveis recordações, tanto das coisas que vimos quanto de outras tantas que fizemos, e de forma prazerosa. Como ficávamos entretidos ao ver nosso pai torneando peças, fazendo medidas com o paquímetro, analisando como desempenaria um chassi ou mesmo fazendo funcionar um motor que acabara de montar, entre tantas outras coisas. Em paralelo a tudo isso, nossa participação, na condição de limitado ajudante aprendiz, era de entrega total, embevecido com tudo aquilo que podíamos fazer. Fazíamos com dedicação e prazer. Com o mesmo prazer de um adolescente que brinca com o seu brinquedo favorito. Mas guardamos 
essas boas lembranças, e também aprendizados, que vez por outra evidenciamos na tentativa de resolver situaçõesproblema que nos aparecem no dia-a-dia.

Ao contrário, na escola, onde até tivemos experiências interessantes, a recordação mais viva guardada na memória foram os momentos "sacrificados" das horas de lazer, já que tínhamos os deveres de casa para fazer, e isso nos "roubava" tempo. É como se nos sentíssemos lesados na condição de adolescente, já que não sentíamos prazer algum ao realizar aquelas tarefas.

Às vezes, quando se tratava de alguma atividade mais prática, individual ou em grupo, existia alguma dedicação, mas hoje observamos que esta vinha muito mais por ser uma atividade prática ou pela convivência com o grupo (a equipe) do que mesmo por se tratar de algo significativo, já que se tratava de trabalhos sobre conteúdos muito distantes do nosso cotidiano, a exemplo dos estudos feitos sobre o projeto Apolo IX apresentado numa feira de ciências.

O tempo passou e veio o curso científico (ensino médio), hora de aprofundar nos estudos (sobretudo nos conteúdos das ciências naturais, que despertava naturalmente como sendo nossa área de interesse) e desvendar os mistérios das Ciências. E a nós, nesse período, fora apresentada uma Ciência, que hoje rotulamos como algo pronto, acabado e essencialmente feito por gênios. Lembramo-nos das aulas de laboratório e das atividades que éramos solicitados a fazêlas, sempre seguindo uma rotina de comandos (roteiro da experiência) no sentido de apenas verificarmos o fenômeno (constatação do óbvio). Confessamos que o mais interessante naquele momento era o procedimento propriamente dito, e o menos importante, talvez, fossem as conclusões do trabalho experimental. Entretanto recordamo-nos de uma aula prática de Física que muito nos marcou. Nessa aula o professor nos apresentou o protótipo de um motor de automóvel. Essa aula ainda guardamos na memória. Se não fosse a timidez, teríamos "assumido" o lugar do professor. Sentimos naquele momento uma vontade imensa de "gritar" para todos: "Isso aí eu entendo, já vi vários, de verdade ... conheço todas as peças." Falava-se de conhecimentos científicos que tinham a ver com vivências do nosso cotidiano. Falava-se de algo que tinha significado para nós.

Diante do exposto, fazemos algumas indagações: que contribuição traz, para a formação do cidadão, um modelo de ensino pautado num conjunto de enfoques alheios à realidade dos estudantes? Como o ensino de Ciências pode contribuir para minimizar o alto grau de ignorância científica em nosso país? Como colaborar para um aprendizado significativo se não organizamos seqüências didáticas que privilegiem as experiências de vidas dos aprendizes? Como a escola pode favorecer ao estudante uma (re)construção de visão de mundo através do ensino de ciências?

Posicionamo-nos, ao longo deste texto, diante dessas e outras indagações que apontam para situações emergenciais que assolam o ensino de Ciências no Brasil e nos convocam a refletir sobre o desafio de ensinar Ciências neste século, que surge em meio aos profundos e rápidos avanços técnico-científicos oriundos sobretudo do século passado. Para tanto, necessário se faz tecer algumas considerações sobre o ensino de Ciências no que diz respeito a aspectos que julgamos fundamentais nos processos de ensino e aprendizagem das consideradas disciplinas científicas, para posteriormente, dentro de um espectro mais amplo e contextualizado, melhor podermos focar a temática em pauta.

\section{ENSINO DE CIÊNCIAS: ALGUMAS CONSIDERAÇÕES SOBRE A EVOLUÇÃO CURRICULAR}

A educação em Ciências na escola básica em nosso país tem sido revelada com características que ao longo do tempo muito pouco tem mudado. Predomina ainda o ensino desvinculado da realidade das pessoas, descontextualizado historicamente, pautado na memorização, e ministrado numa concepção tradicional, na qual o professor, na condição de "sujeito do processo", em aulas expositivas, apresenta e explica os conteúdos. Constata-se, freqüentemente, que quase nada do ensinado em aula é aprendido pelo aluno. Geralmente o aluno não consegue resolver alguma situação que lhe é apresentada, utilizandose de conteúdos trabalhados na escola. Como conseqüência vem o desencanto pela Ciência, a sensação de inutilidade daquilo que fora estudado, o desinteresse e a decepção em perceber que a Ciência estudada nas aulas é divorciada da sua realidade. Como diz Caniato: "O gosto pela ciência vai diminuindo, diminuindo e freqüentemente se extingue. Muitas vezes aquilo que era gosto inerente ao jovem, acaba por se transformar em aversão" [5] (pg. 46).

Não é muito difícil inferir que a escola é a grande responsável por esse quadro desolador esboçado para a educação em Ciências, mostrando-se como uma instituição que ao longo dos tempos não tem cumprido com o seu verdadeiro papel junto à sociedade. Uma instituição cuja missão deveria ser a de educar os sujeitos instrumentando-os para viverem e conviverem livres e democraticamente no mundo que se descortina a sua frente. Isto a escola não tem conseguido fazer, sobretudo levando-se em consideração as mudanças ocorridas nos currículos das disciplinas científicas (Física, Química, Biologia...), bem como a qualidade dos cursos de formação inicial (e continuada) de professores. A nosso ver, são esses os dois pontos básicos que influenciam a qualidade do fazer pedagógico na escola: a formação de professores e o currículo, entendendo este último como um conjunto de elementos culturais que compõem uma proposta político-educativa.

Quanto às mudanças curriculares, estas sempre estiveram, inevitavelmente, atreladas às transformações políticas e sociais ocorridas no Brasil e no mundo. Fazendo uma breve retrospectiva, podemos observar que o ensino de ciências em nosso país é reflexo da situação vivida no mundo ocidental, tendo como grande marco a segunda guerra mundial. O trabalho realizado por Myriam Krasilchik [2] nos dá uma idéia razoável de como os currículos das disciplinas científicas evoluíram na última metade do século passado.

Nesse sentido, tomando como ponto de partida a década de 50, destacamos nesse período a inclusão no currículo dos avanços da Ciência Moderna e a substituição das aulas expositivas por métodos que favoreciam uma participação ativa dos alunos, com grande relevância para as aulas de laboratório nas quais o aprender praticando se constituía no grande objetivo, visando à preparação do futuro cientista. Na década de 60, caracterizada pela Guerra Fria, aconteceu uma importante transformação na estrutura curricular. Ocorreu a introdução do método científico como necessidade para formação do cidadão. Vemos aí a democratização do ensino voltado para o ... "homem comum, que tinha que conviver com o produto da ciência e da tecnologia e do qual se requeria conhecimento, não apenas como especialis- 
ta, mas também como futuro político, profissional liberal, operário, cidadão enfim." [2] (pg. 09).

O período seguinte, os anos 70, foi sinalizado pela crise energética, pelo desenvolvimento industrial descontrolado e pela conseqüente agressão ao meio ambiente, fato que despertou interesse pela educação ambiental. Tudo isso levou a ampliar as discussões, junto aos alunos, sobre as implicações sociais oriundas do progresso científico. Nesse período, porém, o sistema educacional brasileiro é contemplado com a promulgação de uma lei no 5692/71 que obriga a escola secundária a se voltar para a formação de mão-deobra especializada, com o objetivo de atender à demanda do mercado em desenvolvimento. Como conseqüência, as disciplinas científicas foram profundamente violentadas no seu objetivo de contribuir para a formação do homem crítico, cedendo lugar, no nível de importância do currículo, para as disciplinas profissionalizantes, "formadoras" do trabalhador de nível médio.

A década de 80 foi o marco da crise econômica e social que atingiu a maioria dos países subdesenvolvidos e no Brasil, particularmente, dava-se o início de uma transição política de um regime totalitário centralizador para um regime democrático e participativo. Assim, as preocupações no âmbito das atividades educacionais, em especial na educação em Ciências, voltaram-se para a reconstrução da sociedade democrática e para recuperação econômica do país. Nesse sentido, órgãos ligados às áreas de educação, ciência e tecnologia procuraram voltar suas atenções para projetos de melhoria do ensino de Ciências e Matemática, com objetivos de buscar soluções para melhoria do ensino nessas áreas, além de estimular a pesquisa e implementar novas tecnologias. Se por um lado, as melhorias não chegaram às salas de aula (ou chegaram timidamente), por outro lado pudemos vislumbrar nesta época que o ensino das disciplinas científicas passou a ser competência dos pesquisadores da área de ensino de Ciências, o que antes era tarefa dos especialistas em Ciências. Segundo Krasilchik [2],

... formou-se uma nova comunidade
acadêmica - a dos educadores em ciência
- uma área de fronteira entre educação e
ciência, que se preocupa prioritariamente
com o significado das disciplinas científicas
no currículo.
Este campo de conhecimento em formação
está hoje apoiado em associações de classe,
publicaçôes periódicas e cursos de formação
de professores a nível de graduação e pós-
graduação [2] (pg. 14).

Nestas breves considerações a respeito da evolução dos currículos das disciplinas científicas ao longo dos anos, podemos perceber que mudanças curriculares ocorreram (e ainda ocorrem) ao sabor das intercorrências sócio-política e econômicas que atravessavam o mundo ocidental e em especial o Brasil.

Embora esforços e tentativas tenham sido desenvolvidos por pesquisadores no sentido de melhorar o ensino das Ciências no nosso país, muitos desses trabalhos não foram além de publicações. Seus resultados, idéias e intenções sequer chegaram aos centros de decisão, tão pouco às escolas.
No nosso sistema educacional, estruturalmente centralizado, não há tradição de demanda por qualidade pela comunidade, que não participa do processo decisório. Além disso, não há canais eficientes, entre os pesquisadores e o sistema, para cobrar investigações que sejam relevantes para opções relativas ao currículo [2] (pg. 41).

Mudanças ocorrem, por vezes não saem sequer do papel e, quando chegam às escolas, apresentam-se distorcidas na sua idéia central, pobre de detalhes e difícil de entendimento, até porque a quem fundamentalmente interessa e destinase o currículo escolar, estudantes e educadores, têm pouca participação na elaboração dos projetos.

Historicamente, os professores têm sido considerados culpados pelo uso inadequado dos materiais curriculares. A opinião desses profissionais e a sua capacidade de subverter imposições e sugestões oriundas dos órgãos centrais do sistema educacional são aspectos que merecem a atenção daqueles que estão preocupados com o currículo na escola [2] (pg. 40)

O outro aspecto aqui apontado como determinante na práxis pedagógica dos educadores é a sua formação inicial e também a continuação e atualização dos seus estudos. Em que medida cursos de formação de professores de Ciências estão satisfazendo às necessidades formativas desses profissionais? A resposta a esse questionamento parece-nos óbvia quando olhamos para o quadro geral que se desenha para a educação formal no nosso país, em especial para a educação em Ciências, já caracterizada anteriormente aqui neste texto. Basta olhar e constatar a situação caótica e desoladora da educação e ver as conseqüências, cujas causas têm sua origem, possivelmente, na formação de docentes nas Ciências Naturais. Sendo assim, destacamos alguns pontos que nos parecem ser de fundamental importância ou quiçá determinante para a formação em questão.

Um deles é de estrutura curricular, onde, diferentemente de outros países, ainda se concebe a idéia de formação docente como uma soma de duas outras formações isoladas, a científica básica e a educação geral. Essa concepção, no nosso entender, por estabelecer uma certa distância entre conhecimentos científicos e pedagógicos, se constitui num grande obstáculo para uma formação integrada e interdisciplinar do futuro licenciado em Ciências. Na tentativa de romper com a estrutura vigente o Ministério da Educação no ano 2000 remeteu ao Conselho Nacional de Educação [6], para apreciação, proposta de Diretrizes para a Formação de Professores da Educação Básica, em cursos de nível superior, que após reuniões, audiências e discussões se constitui hoje em um documento que norteia as reformas curriculares dos cursos de Licenciatura em todo país. Nesse documento, é visto claramente a nova perspectiva de formação profissional que inverte a lógica da organização curricular atual, tomando como referência básica o conjunto de competências que se quer para o futuro professor. Podemos encontrar essa confirmação no primeiro parágrafo do item 3.5 do documento: 
Para superar a suposta oposição entre o conteudismo e pedagogismo os currículos de formação de professores devem contemplar espaços, tempos e atividades adequadas que facilitem a seus alunos fazer permanentemente a transposição didática, isto é, a transformação dos objetos de conhecimento em objetos de en$\operatorname{sino}[6]$.

Nessa perspectiva, é de fundamental importância a atuação integrada da equipe de professores formadores, objetivando garantir o equilíbrio e a interrelação dos conteúdos (práticos, pedagógicos e de conhecimento específico) trabalhados ao longo dos cursos de formação docente, com vistas a formar lideranças, agentes de mudanças, profissionais competentes, desafiadores, dispostos a assumir riscos buscando construir um mundo melhor através do seu fazer pedagógico.

Outros pontos, decorrentes de desdobramentos do próprio currículo, relacionam-se com a metodologia predominante nos cursos de licenciatura: as aulas assumem um caráter expositivo, favorecendo a passividade dos alunos, futuros professores; observa-se a utilização excessiva de questões-padrão, o que não oportuniza a abordagem de novas situações; as práticas de laboratório são pautadas apenas no processo de simples verificação e constatação de leis, conceitos, valores, ..., já estabelecidos e referendados no campo do conhecimento científico, sem abrir margens para o observar e o pensar; o vasto conteúdo a ser abordado em função do tempo, que impossibilita um mergulho em profundidade na especificidade dos conhecimentos, bem como na interrelação com outras áreas do saber.

É necessário pensar num currículo para formação de professores em Ciências que ofereça elementos no sentido de solucionar os problemas supra citados, além de outros, objetivando favorecer ao estudante uma formação compatível com as necessidades formativas de um educador. Entretanto esta preparação à docência não deve limitar-se apenas a formação inicial, mas estender-se para além desta, na perspectiva de um trabalho continuado concebido como um processo coletivo e permanente de professores em atividade. Isso porque:

A necessidade de formação permanente surge associada, em um primeiro momento, às próprias carências da formação inicial, porém, existe uma razão de maior peso pela qual se deve reiterar sua necessidade. De fato a tendência atual nos países com um sistema educativo mais avançado não consiste em ampliar a formação inicial ou "pre-service" - sempre insuficiente - mas em estabelecer estruturas de formação permanente [7] (pg. 777).

Como se trata de uma tendência investigativa no campo das pesquisas em educação, podemos encontrar na literatura diversos trabalhos que apresentam propostas alternativas de currículos para a formação de professores.

Com a pretensão de não nos distanciar do tema proposto, no momento não trataremos de tais propostas. Porém, apenas para falar um pouco de necessidades formativas do professor de Ciências, gostaríamos de ressaltar nesta área o trabalho de Carvalho e Gil-Pérez [7] e mais precisamente quando eles na "introdução" da sua obra, destacam algumas dessas necessidades tais como:
... o conhecimento da matéria a ser ensinada, os conhecimentos teóricos sobre a aprendizagem das ciências, a preparação de atividades, a orientação do trabalho dos alunos $e$ a avaliação.

... o conhecimento das concepções espontâneas dos docentes (cujo papel na formação do professor é tanto ou mais relevante que o das concepções espontâneas dos alunos em sua aprendizagem), a análise crítica do ensino tradicional (superando as desqualificações simplistas) e a iniciação à pesquisa [7] (pg. 10).

\section{ENSINO DE FÍSICA: PARA ENTENDER O MUNDO EM QUE VIVEMOS}

Na busca por entender o mundo em que vivemos, estamos, constantemente, sendo desafiados. Desafios que começam na fase sensório-motora, quando se dá a evolução da nossa percepção e motricidade, estendendo-se por toda nossa vida, de diversas e complexas formas. O que antes se constituía apenas em necessidades de sobrevivência, com o passar do tempo, tornam-se desafios mais constantes e consistentes, passando a exigir de nós maior competência com vistas a entender e solucionar situações advindas.

Como conseqüência dessa longa caminhada de freqüentes desafios e situações vividas, neste mundo de constantes mudanças, construímos, fruto de nossas experiências, os nossos saberes. Sendo assim, na condição de detentor desses conhecimentos, passamos a sentir necessidade de (re)elaborar e/ou querer ampliar a nossa visão de mundo, como diz Pietrocola [8].

Seja por interesse pessoal, por necessidades materiais, por valorização social, ou outro motivo qualquer, ampliamos, modificamos e, eventualmente, substituímos esta visão de mundo ao longo de nossas vidas. Neste processo, buscamos dar sentido às situações vivenciadas, ou seja, aos desafios enfrentados. Mobilizamos todas as formas disponíveis de entendimento, incluindo-se aí crenças e ideais pessoais, tradições familiares e culturais, entre outras, num mútuo ajuste entre o mundo exterior e o nosso mundo interior. Entram em jogo as diversas facetas da nossa consciência, sejam elas racionais, sentimentais, emocionais, mediadas pela visão de mundo já construída [8].

É esse sujeito repleto de crenças, tradições e calcado num conjunto de saberes que chega à escola. E a esta cabe a enorme tarefa de contribuir para a formação desse indivíduo, no sentido de (re)construir e/ou ampliar adequadamente a sua visão de mundo, a partir dos seus conhecimentos prévios, transcendendo ao que geralmente chamamos de senso comum. Assim, o papel da escola é de pôr em prática um currículo que oportunize ao estudante construir seus conhecimentos, levando em consideração as vivências e experiências acumuladas ao longo de sua vida. A escola, portanto, deve ser um espaço que garanta ao aluno a sistematização e o acesso a diversas formas de conhecimento, entre eles o científico, cuja especificidade o credencia como 
grande ferramenta para sobrevivência do homem no mundo moderno.

Mas, se por um lado, o homem moderno necessita da escola com essas características, por outro lado o ensino de Ciências, e em especial da Física, a rigor, com raríssimas exceções, não tem cumprido o seu devido papel de privilegiar conteúdos e métodos que favoreçam a construção contextualizada de saberes fundamentais à vida e ao entendimento do mundo.

Estuda-se nas escolas uma Ciência Física "particular", para um mundo virtual (de pontos materiais, sem atritos, sem resistências, ...) cheio de condições de contorno onde fórmulas e expressões matemáticas ganham destaque em detrimento aos conceitos físicos, afastando-se cada vez da Física existente no nosso mundo. Conteúdos estudados assim, passam-nos a idéia de inutilidade, de cultura inútil diante de um mundo repleto de constantes e permanentes desafios. Em suma, o mundo físico que nos cerca, em constante avanço tecno-científico requer da escola muito mais do que ela tem dado. Requer da escola uma educação científica que objetive capacitar o aprendiz, técnica e cientificamente, dando-lhe condições efetivas para responder aos constantes desafios propostos pelo mundo contemporâneo. Infelizmente, embora constatemos nas escolas projetos pedagógicos bem elaborados e adequados às exigências do mundo atual - preparar para a formação cidadã - verificamos na prática, no dia-a-dia da escola, uma preocupação excessiva com a preparação para os exames seletivos para ingresso nos cursos superiores: Vestibulares, "anunciados como inocentes portas de entrada, o seu efeito maior, entretanto, tem sido o seu poder de moldar e determinar os padrões de educação nas escolas de ensino médio e até mesmo de ensino fundamental" [9] (pg. 15).

Como conseqüência disso, vemos uma Física estudada em sala de aula, pouco relacionada com o cotidiano dos indivíduos. Uma Física cujos conteúdos são utilizados, na maioria das vezes, apenas para cumprir exigências impostas pelo sistema escolar vigente, como obter notas para passar de unidade, passar de ano, passar no vestibular, mas que não garante "passar na vida", quando requisitados a explicar fenômenos corriqueiros, resolver situaçõesproblema do cotidiano, entender o funcionamento de determinados aparatos, decidir sobre a aquisição de um aparelho ..., situações essas que evidenciam o grau de analfabetismo científico (conhecimento de noções básicas da Ciência) em que se encontra a nossa população jovem escolarizada. Fato que é confirmado através da pesquisa realizada pelo Programa Internacional de Avaliação de Estudantes da Unesco, junto a 43 países, comparando o desempenho de estudantes, com 15 anos de idade, relativo a conhecimentos científicos básicos. O Brasil ocupou a $42^{\mathrm{a}}$ posição. Com certeza, um resultado nada animador. Uma situação que coloca em cheque a educação em Ciências desenvolvida nas escolas, aqui já bastante comentada. Com efeito, é preciso, urgentemente, reavaliar os currículos das disciplinas científicas. Rever conteúdos programáticos e métodos visando contribuir para o desenvolvimento pessoal e social dos indivíduos, além de favorecer a utilização dos conteúdos estudados na sua vida cotidiana, proporcionando, dessa forma, aos sujeitos da aprendizagem, os alunos, uma formação cidadã compatível com as necessidades e desafios do mundo em que vivem. Confirmamos isso nas palavras de Celso Antunes, quando ele diz:
Muito se fala, atualmente, na importância inadiável de se transformar informações em conhecimento e de se permitir que o aluno leve para rua e, portanto, para sua vida e seu entorno, os saberes que na escola aprende. Mas se a estrutura da aula tradicional não mudar, de nada adianta clamar pelos novos tempos, aprendizagem significativa, habilidades operatórias e o despertar de capacidades, competências e inteligências [10].

Como podemos observar nas palavras de Antunes, urge sairmos do discurso, se desejamos um ensino de qualidade e uma aprendizagem significativa. É preciso nas nossas ações, enquanto professor, propormos seqüências de atividades nas quais os "conteúdos" não sejam encarados apenas como fatos e conceitos, mas também na dimensão procedimental do saber fazer e na formação de atitudes através de conteúdos atitudinais. Porém, para que esses conteúdos sejam construídos, necessário se faz recorrermos aos conhecimentos prévios dos alunos e ajudá-los a construir a compreensão de novos conceitos a partir da informação de conhecimentos. Nesse sentido, ampliar a nossa concepção sobre conteúdo é fundamental. Na medida em que entendemos que conteúdo não se restringe, apenas, ao elenco de assuntos programados para uma dada disciplina, estamos avançando na direção de um fazer pedagógico que possibilite ao estudante, além da aquisição de dados e a compreensão de conceitos, também conhecer formas de atuar e de usar o conhecimento, bem como refletir sobre si mesmo e suas atitudes no mundo físico que o cerca. Se queremos levar nossos alunos a esse estágio de potencialidades, precisamos educá-los no sentido de construir conhecimentos que lhes garantam acesso ao mundo real. Realidade essa que está atrelada aos elementos constituintes do mundo e que pode variar em função de necessidades, interesses e contextos de cada sujeito, como também das possíveis relações entre os objetos existentes nesse mundo.

Entretanto, na busca de entender esse mundo físico que nos cerca, é fundamental para o professor conhecer a evolução das idéias científicas, buscando compreender como estas idéias podem contribuir para entender a Ciência como um recorte da realidade, na relação com outras atividades humanas. Concordando com Anjos [11], é a partir do conhecimento da evolução do pensamento científico, dos obstáculos encontrados ao longo do seu desenvolvimento, que o professor poderá entender melhor as dificuldades de seus alunos na construção de certos conceitos, já que, outrora, estudiosos da Ciência, em particular da Física, usaram caminhos semelhantes na tentativa de entender e conceituar determinados fenômenos.

Assim, é salutar também para o aluno compreender como o conhecimento científico evoluiu ao longo dos tempos e como os estudiosos da Ciência contribuíram para construção desses saberes. Essa compreensão pode proporcionar ao aluno um novo olhar sobre a Ciência no sentido vê-la como uma área do conhecimento humano historicamente construída por pessoas como nós, pautado em buscas, tentativas, erros e acertos, atitudes e procedimentos de homens e mulheres que, no exercício de fazer Ciência, pensam, investigam, imaginam, concluem, como nós fazemos diante de situações-problema. 


\section{CONSIDERAÇÕES FINAIS}

As considerações tecidas ao longo deste texto apontam para diversos fatores que interferem nos processos de ensino e aprendizagem em Ciências. Sejam fatores originais como currículo e formação de professores, sejam fatores decorrentes deles, como metodologia e concepção de conteúdos, por exemplo, que se constituem em importantes elementos, complicadores ou facilitadores, do fazer pedagógico desenvolvido nas escolas, voltado para uma educação científica que contribua para a formação cidadã plena, para o usufruto da cultura e para o trabalho digno e humano. Assim sendo, é necessário que a escola busque desenvolver, junto aos alunos, ações no sentido de construir habilidades para enfrentarem este mundo em franca e contínua evolução tecno-científica. Podemos confirmar isto na citação que segue:

As mudanças já promovidas no sistema produtivo e nos serviços não deixam dúvida de que, ao longo do século XXI, quem ainda não estiver trabalhando não estará realizando tarefas rotineiras repetitivas ou brutas, pois essas serão realizadas com vantagem por máquinas automáticas e sistemas informatizados. Isso quer dizer que para participar da produção serão necessários precisamente os atributos que as máquinas não possuem, como afetividade, expressividade, criatividade, sentido de empreendimento, solidariedade e espírito de grupo, assim como cultura artística e científica [12].

É, por conseguinte, um novo cenário que se descortina e exige um novo olhar sobre a educação e em especial sobre a educação científica neste século. Uma educação em Ciências que requer da escola ações que, efetivamente, possibilitem aos aprendizes, um novo entendimento sobre a natureza humana, sobre a concepção de conhecimento e de aprendizado. Nesse sentido, segundo Menezes [12], a escola deve procurar se atualizar levando em conta que: a promoção de todos os alunos deve ocorrer, já que todos podem aprender; o aprendizado é uma ação resultante de quem (e não sobre quem) aprende; sejam respeitadas as diferenças individuais entre os alunos, sem a pretensão de torná-los idênticos. Esses fatores apontam para um entendimento sobre a educação pautado em valores humanos, ainda tão pouco cultivado nas escolas hoje em dia, podem mudar e muito o panorama da educação formal em geral, particularmente, a educação em Ciências, se realmente for incorporado ao fazer pedagógico do professor, contribuindo assim, significamente, para a melhoria da qualidade do ensino das Ciências da Natureza, uma vez que, ao promover discussões envolvendo questões reais de ordem sócio-econômicas, o ensino de Ciências se aproxima, cada vez mais, das Ciências Humanas e Sociais, fato que reforça a concepção da Ciência enquanto construção humana. Nesse sentido, é fundamental envolver a classe em efetivas discussões de situações-problema reais da sua comunidade, oportunizando o entendimento de que o aprendizado das Ciências não está em dicotomia com os valores humanos.

No momento em que optarmos por uma práxis pedagógica centrada no educando, desistindo, assim, da concepção bancária e enciclopédica do ensino pautada na transmissão de informações, certamente estaremos criando oportunidades para que, através do estudo de questões atuais e de interesse geral da comunidade, os alunos possam desenvolver suas capacidades de criar, de argumentar, de pensar, .... de propor, preparando-se, dessa forma, para o mundo, para o trabalho..., para a vida.

Vale salientar, e lembrar também, que uma ação pedagógica centrada no aluno requer, entre outras coisas, e primordialmente, levar em consideração o que o indivíduo traz consigo, em relação ao conhecimento historicamente construído na sua relação com os meios físico e social, buscando garantir um aprendizado significativo. Nesse sentido,

\begin{abstract}
... para um ensino efetivo dos conteúdos da física, com conceitos, leis e princípios formalizados, torna-se fundamental e de suma importância saber o que os alunos trazem estruturados a nível desses conteúdos, conhecer o que eles pensam sobre princípios a serem trabalhados, além de considerar a capacidade de pensamento estruturado. Compreender, então, o significado das concepções espontâneas do indivíduo, requer não ficarmos egoisticamente fechados ao nosso ponto de vista de especialistas numa determinada área do conhecimento científico [11].
\end{abstract}

Essas palavras reforçam não só a necessidade de se levar em consideração as concepções prévias dos indivíduos no ato pedagógico, como também procurar compreendê-las em seu significado. Fato que certamente pode contribuir para o professor (re)organizar suas estratégias de ensino visando proporcionar ao aluno condições necessárias para o seu desenvolvimento pleno, não se limitando a fornecer-lhe respostas prontas, mas sim oportunizando-lhe exercitar, pensar e a tomar decisões à luz dos conhecimentos científicos estudados em sala de aula.

1 (2004).

[5] R. Caniato; Com Ciência na educação, $2^{\mathrm{a}}$ ed. Papirus (1989).

[6] Ministério da Educação, Conselho Federal de Educação, Brasil (2000).

[7] A.M.P. de Carvalho, D. Gil-Pérez; A formação de professores de Ciências, Cortez Editora (1993).

[8] M. Pietrocola; Construção e realidade: o papel do conhecimento científico no entendimento do mundo, In: M. Pietro- 
cola (org.) Ensino de física: conteúdo, metodologia e epistemologia numa concepção integradora, Editora da UFSC. pg. 9 (2001).

[9] R. Alves; Estórias de quem gosta de ensinar, $8^{\mathrm{a}}$ ed. Papirus, Campinas, pg. 168 (2003).

[10] C. Antunes; Marinheiros e Professores II: diálogos surrealistas, Editora Vozes (2002).

[11] A.J.S. dos Anjos; Concepções intuitivas dos alunos: um es- tudo a partir da relação força e movimento, Dissertação de Mestrado apresentada à Faculdade de Educação da Universidade Federal da Bahia, BA. (Não-publicada) (1996).

[12] L.C. de Menezes; Ensinar Ciências no próximo século, In: E.W. Hamburguer, C. Matos, (orgs.) O desafio de ensinar Ciências no século XXI, Edusp pg. 48 (2000). 